\title{
Increasing the Efficiency of the Autothermal Processing of Coal in a Fluidized Bed
}

\author{
Dmitry A. Loginov, \\ Sergey V. Demenchuk and Sergey R. Islamov* \\ Branch of Sibniiugleobogashenie LLC in Krasnoyarsk \\ Krasnoyarsk, Russian Federation
}

Received 07.04.2021, received in revised form 12.05.2021, accepted 21.06.2021

\begin{abstract}
The results of work on increasing the efficiency of heat energy production in standard boiler units using the «TERMOKOKS-KS» technology by intensifying the energy-technological processing of coal in a fluidized bed are presented. A significant increase in productivity has been established when removing small grades from coal and subsequent drying of coal, which makes it possible to reduce the cost of the obtained heat energy. The coarsening of the particles of the obtained browncoal coke with a decrease in the moisture content of the coal was revealed, which increases its transport characteristics. The range of temperatures of stable operation of the fluidized bed has been increased, due to which the product range of the «TERMOKOKS-KS» process has been expanded. The heat and material balances of the processes of combined production of heat energy and carbon-containing products are presented.
\end{abstract}

Keywords: fluidized bed, Termokoks, browncoal coke, semi-coke.

\section{Повышение эффективности процесса}

\section{автотермической переработки угля в кипящем слое}

\author{
Д.А. Логинов, С. В. Деменчук, С. Р. Исламов \\ Филиал ООО «Сибнииуглеобогащение» в Красноярске \\ Российская Федераиия, Красноярск
}

Аннотация. В статье приведены результаты работ по повышению эффективности производства тепловой энергии в типовых котельных агрегатах по технологии «ТЕРМОКОКС-КС» путем интенсификации энерготехнологической переработки угля в кипящем слое. Установлено

(C) Siberian Federal University. All rights reserved

This work is licensed under a Creative Commons Attribution-Non Commercial 4.0 International License (CC BY-NC 4.0).

* Corresponding author E-mail address: LoginovDA@suek.ru, IslamovSR@suek.ru 
значительное повышение производительности при удалении из угля мелких классов и последующем подсушивании угля, что позволяет снизить себестоимость получаемой тепловой энергии. Выявлено укрупнение частиц получаемого буроугольного кокса при уменьшении влаги угля, что повышает его транспортные характеристики. Увеличен диапазон температур стабильной работы кипящего слоя, благодаря чему расширена номенклатура продукции процесса «ТЕРМОКОКС-КС». Представлены тепловые и материальные балансы процессов комбинированного производства тепловой энергии и углеродсодержащих продуктов.

Ключевые слова: кипящий слой, термококс, буроугольный кокс, полукокс.

Цитирование: Логинов, Д.А. Повышение эффективности процесса автотермической переработки угля в кипящем слое / Д. А. Логинов, С. В. Деменчук, С. Р. Исламов // Журн. Сиб. федер. ун-та. Техника и технологии, 2021, 14(4). С. $408-415$. DOI: $10.17516 / 1999-494 X-0321$

\section{Введение}

Технологический принцип производства тепловой энергии путем прямого сжигания угля остается неизменным со времен промышленной революции в Европе и по сути достиг своего предела экономической и экологической эффективности. Адаптация используемых в настоящее время энергетических котлов под современные экологические реалии труднореализуема и требует значительных вложений на закупку очистных устройств и утилизацию золошлаковых отходов, что в конечном счете сказывается на себестоимости энергетической продукции. В связи с этим особенно актуальна задача разработки и внедрения принципиально новых, энергетически и экономически эффективных, экологически безопасных и высокопроизводительных способов производства энергии [1]. Высокая экономическая эффективность может быть достигнута только при использовании принципа комбинированного производства энергоносителей с высокой потребительской стоимостью.

В области энергетического использования угля огромный потенциал имеет технология автотермической переработки угля в кипящем слое «ТЕРМОКОКС-КС» [2], в рамках которой возможно осуществление комбинированного производства тепловой энергии и углеродистых материалов.

На текущий момент технология реализована на котельной $\mathrm{AO}$ «Разрез Березовский» (г. Шарыпово, Красноярский край) путем встраивания реактора с кипящим слоем в топку типовых котельных агрегатов (КТВС-20). После модификации котла одновременно осуществляются процессы частичной газификации угля со сжиганием образующегося газового топлива для получения тепловой энергии и параллельного получения буроугольного кокса (БК) [3]. Котельный агрегат, сохраняя паспортные энергетические характеристики, имеет улучшенные экологические показатели по газовым выбросам, а вместо золошлаковых отходов производит ценный энергетический продукт, который используется для производства брикетов металлургического назначения, бездымного топлива, а также в ряде других приложений, например, в качестве сорбента в технологии гидрокрекинга.

Технология «ТЕРМОКОКС-КС» разработана относительно недавно, поэтому ее техникоэкономический потенциал раскрыт не полностью. В настоящей работе приводятся способы повышения эффективности производства тепловой энергии в котельном агрегате при автотермической переработке угля в кипящем слое. С экономической точки зрения целесообразно увеличение доли буроугольного кокса в составе производимой энергетической продукции (буроугольный кокс + тепловая энергия). При этом эксплуатационные затраты возможно отнести

$$
-409-
$$


на себестоимость дорогостоящего БК и радикально снизить себестоимость получаемой тепловой энергии.

\section{Материалы и методы исследований}

На первом этапе на экспериментальном стенде [4] были проведены сравнительные испытания березовского угля различных классов крупности. С целью повышения удельной производительности процесса по БК в расчете на единицу товарной тепловой энергии на экспериментальном стенде были проведены испытания по термической переработке березовского угля с предварительным удалением мелкого класса. В промышленных условиях технически осуществимым представляется удаление из потока угля мелочи менее 5 мм, поэтому в дальнейших испытаниях применялся уголь крупностью 5-15 мм.

Типичные характеристики угля, использованного в экспериментах, отражены в табл. 1.

На рис. 1 приведена зависимость удельной производительности от температуры кипящего слоя. На рис. 2 показаны гранулометрические кривые, полученные в результате ситового анализа полученных образцов БК. В табл. 2 приведены характеристики получаемого кокса, в табл. 3 представлен материальный и энергетический баланс процесса с применением угля 5-15 мм при температуре $700{ }^{\circ} \mathrm{C}$.

В работе [5] было показано, что применение угля Бородинского месторождения с пониженной влагой приводит к увеличению относительного выхода производимой в котле кипящего слоя продукции с сопутствующим укрупнением продукта. Далее с целью определения

Таблица 1. Технический и элементный анализ исходного угля

Table 1. Technical and elemental analysis the original coal

\begin{tabular}{|c|c|c|c|c|c|c|c|c|}
\hline$W_{t}^{r}$ & $A^{d}$ & $V^{\text {daf }}$ & $C^{\text {daf }}$ & $O^{\text {daf }}$ & $H^{\text {daf }}$ & $N^{\text {daf }}$ & $S_{t}^{d}$ & $Q_{i}^{r}$ \\
\hline \multicolumn{8}{|c|}{$\%$} & МДж/кГ \\
\hline 33,8 & 4,9 & 47,6 & 71,1 & 23,1 & 4,9 & 0,7 & 0,15 & 15,9 \\
\hline
\end{tabular}

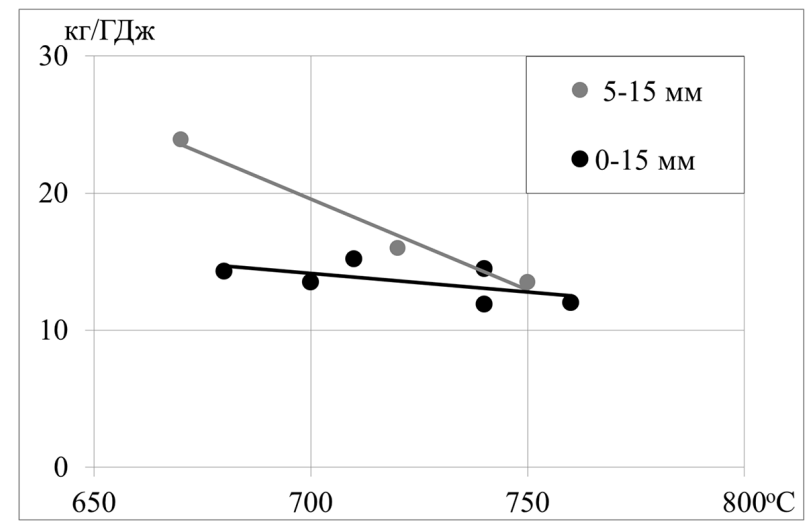

Рис. 1. Зависимость удельной производительности от температуры кипящего слоя

Fig. 1. Dependence of specific productivity on fluidized bed temperature

$$
-410-
$$




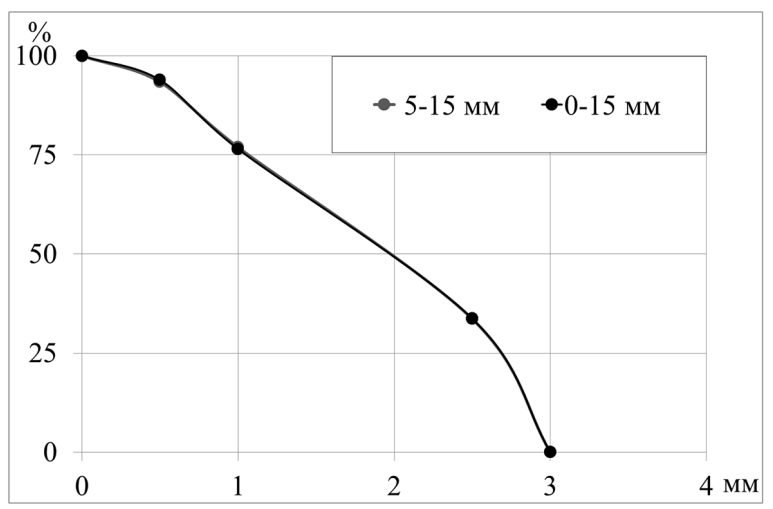

Рис. 2. Гранулометрический состав БК

Fig. 2. Granulometric composition of BC

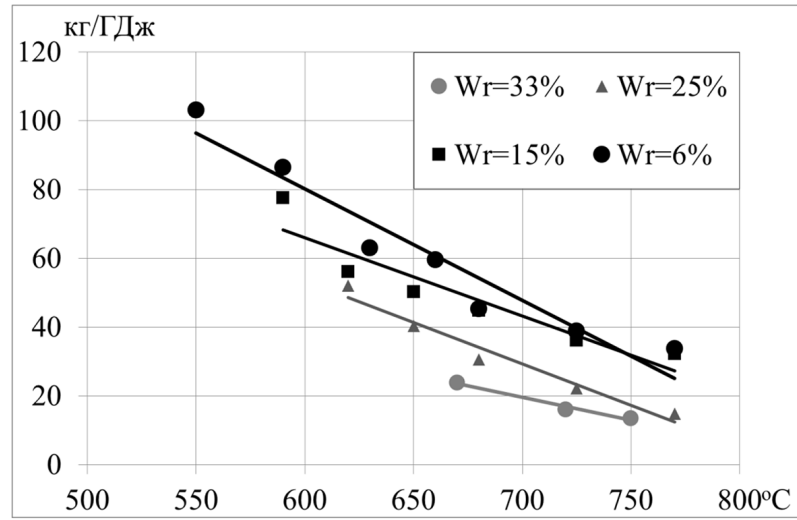

Рис. 3. Зависимость удельной производительности от температуры кипящего слоя

Fig. 3. Dependence of specific productivity on fluidized bed temperature

Таблица 2. Характеристики получаемых твердых продуктов

Table 2. Characteristics of the obtained solid products

\begin{tabular}{|c|c|c|c|c|c|c|c|c|}
\hline Параметр & \multicolumn{8}{|c|}{ Значение } \\
\hline Класс крупности угля, мм & \multicolumn{7}{|c|}{$5-15$} & $0-15$ \\
\hline Общая влага угля, \% & \multicolumn{2}{|c|}{6,0} & \multicolumn{2}{|c|}{15,0} & \multicolumn{2}{|c|}{25,0} & \multicolumn{2}{|c|}{33,8} \\
\hline Температура, ${ }^{\circ} \mathrm{C}$ & 680 & 560 & 680 & 610 & 680 & 630 & 680 & 680 \\
\hline \multicolumn{9}{|c|}{ Технический анализ БК/БПК, \% } \\
\hline $\mathrm{W}^{\mathrm{r}}$ & 0,0 & 0,0 & 0,0 & 0,0 & 0,0 & 0,0 & 0,0 & 0,0 \\
\hline $\mathrm{A}^{\mathrm{d}}$ & 8,1 & 6,7 & 9,0 & 7,4 & 8,3 & 7,0 & 9,7 & 10,0 \\
\hline $\mathrm{V}^{\mathrm{daf}}$ & 5,7 & 20,1 & 4,1 & 15,4 & 6,6 & 10,1 & 6,5 & 5,5 \\
\hline $\mathrm{Q}^{\mathrm{r}}, \mathrm{MДж/кг}$ & 29,6 & 28,4 & 29,5 & 28,1 & 29,0 & 28,0 & 29,4 & 29,0 \\
\hline
\end{tabular}


Таблица 3. Материальный и энергетический баланс процессов

Table 3. Material and energy balance of processes

\begin{tabular}{|c|c|c|c|c|c|c|}
\hline \multirow{2}{*}{ Параметр } & \multicolumn{6}{|c|}{ Температура кипящего слоя, ${ }^{\circ} \mathrm{C}$} \\
\hline & \multicolumn{2}{|c|}{680} & \multicolumn{2}{|c|}{670} & \multicolumn{2}{|c|}{550} \\
\hline Класс крупности угля, мм & \multicolumn{6}{|c|}{$5-15$} \\
\hline Общая влага угля, \% & \multicolumn{2}{|c|}{33,8} & \multicolumn{2}{|c|}{6,0} & \multicolumn{2}{|c|}{6,0} \\
\hline \multicolumn{7}{|c|}{ Материальный баланс } \\
\hline & $\mathrm{T}$ & $\mathrm{M}^{3}$ & $\mathrm{~T}$ & $\mathrm{M}^{3}$ & $\mathrm{~T}$ & $\mathrm{M}^{3}$ \\
\hline \multicolumn{7}{|l|}{ Приход } \\
\hline Уголь & 1,0 & - & 1,0 & - & 1,0 & - \\
\hline из него в кипящий слой & 1,0 & - & 0,7 & - & 0,7 & - \\
\hline Воздух & 3,62 & 2806,3 & 2,05 & 1593,6 & 1,479 & 1146,3 \\
\hline Итого & 4,62 & 2806,3 & 2,75 & 1593,6 & 2,179 & 1146,3 \\
\hline \multicolumn{7}{|l|}{ Расход } \\
\hline Термококс & 0,20 & - & 0,35 & - & 0,42 & - \\
\hline Дымовые газы & 4,42 & 3487,6 & 2,40 & 1877,7 & 1,754 & 1379,8 \\
\hline Итого & 4,62 & 3487,6 & 2,75 & 1877,7 & 2,179 & 1379,8 \\
\hline \multicolumn{7}{|c|}{ Энергетический баланс } \\
\hline & ГДж & $\%$ & ГДж & $\%$ & ГДж & $\%$ \\
\hline Приход & 15,9 & 100,0 & 16,5 & 100,0 & 16,5 & 100,0 \\
\hline Итого & 15,9 & 100,0 & 16,5 & 100,0 & 16,5 & 100,0 \\
\hline \multicolumn{7}{|l|}{ Расход } \\
\hline Теплота сгорания термококса & 5,7 & 36,0 & 10,3 & 62,6 & 12,1 & 73,1 \\
\hline Тепловая энергия сгорания летучих & 9,9 & 62,5 & 5,7 & 34,9 & 4,0 & 23,9 \\
\hline Энтальпия термококса & 0,3 & 1,5 & 0,4 & 2,5 & 0,5 & 3,0 \\
\hline Итого & 15,9 & 100,0 & 16,5 & 100,0 & 16,5 & 100,0 \\
\hline
\end{tabular}

влияния влажности топлива на характеристики процесса, свойства получаемых продуктов, материальный и энергетический балансы в экспериментах использован предварительно подсушенный березовский уголь с различной исходной влагой $(6,15,25,33$ \%). Результаты отражены на рис. 3-6. В табл. 2 можно видеть характеристики получаемого БК, в табл. 3 - материальный и энергетический баланс процесса получения БК и буроугольного полукокса (БПК) из угля 5-15 мм с влагой $\mathrm{Wr}=6,0$ \% при температурах 700 и $550{ }^{\circ} \mathrm{C}$.

\section{Обсуждение результатов}

В результате экспериментальных исследований установлено (рис. 1), что удельный выход буроугольного кокса с требуемыми характеристиками при использовании угля класса крупности 5-15 мм увеличился с 14 до 23 кг/ГДж. При этом температурный интервал термической переработки для обеспечения показателей зольности $\mathrm{A}^{\mathrm{d}}$ и выхода летучих веществ $\mathrm{V}^{\mathrm{daf}}$ на уровне $10 \%$ составил 670-700 ㄷ. При попытках снижения температуры наблюдалось нарушение стабильности функционирования кипящего слоя. 


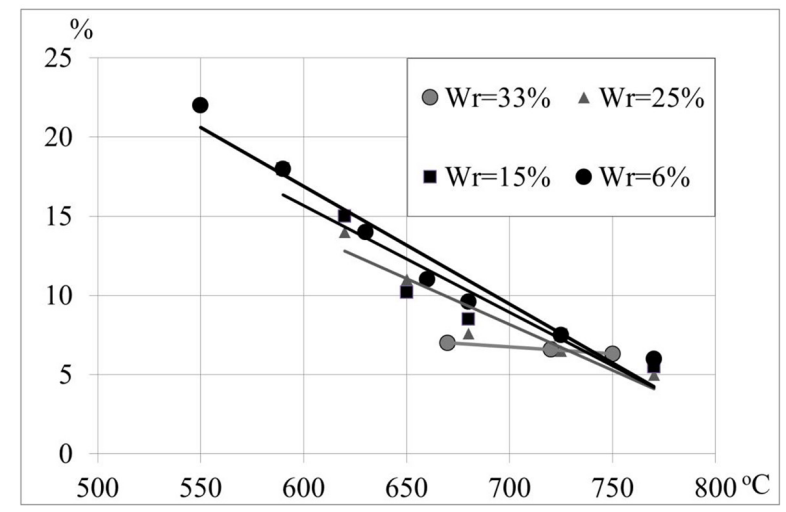

Рис. 4. Зависимость выхода летучих веществ БК от температуры кипящего слоя

Fig. 4. Dependence of the yield of volatile substances of BC on the temperature of the fluidized bed

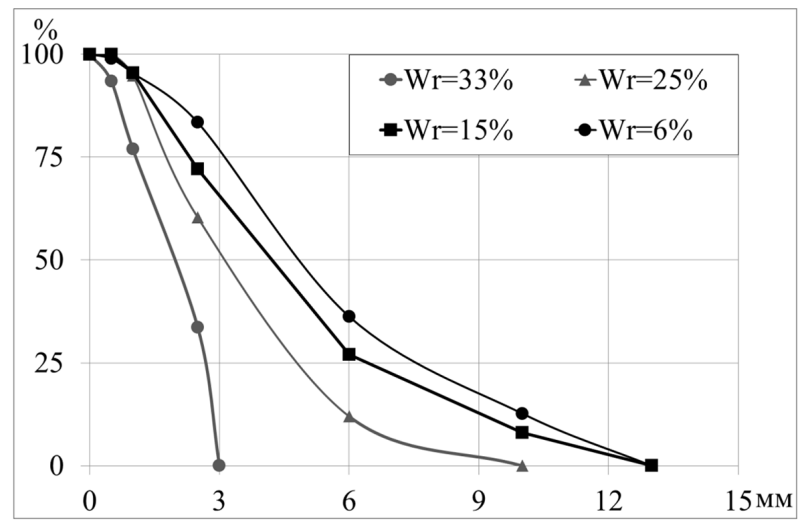

Рис. 5. Средний гранулометрический состав БК из угля с различной влагой в диапазоне температур 670$700{ }^{\circ} \mathrm{C}$

Fig. 5. Average granulometric composition of $\mathrm{BC}$ made of coal with different moisture in the temperature range $670-700{ }^{\circ} \mathrm{C}$

Также выявлено, что гранулометрический состав получаемого БК в проведенных экспериментах не зависит от класса крупности применяемого угля (рис. 2). Эффект термодробления при попадании частиц топлива в зону высоких температур кипящего слоя оказывает определяющее влияние на гранулометрический состав кокса. Таким образом, даже удаление из сырого угля мелких классов не позволяет получить в кипящем слое кокс с более крупным размером частиц.

Как видно на рис. 3, предварительная сушка угля позволила более чем вдвое увеличить удельный выход БК - с 23 до 55 кг/ГДж в рекомендованном ранее температурном интервале $\left(670-700{ }^{\circ} \mathrm{C}\right)$. Зольность $\mathrm{A}^{\mathrm{d}}$ и выход летучих $\mathrm{V}^{\mathrm{daf}}$ в этом диапазоне также остались ниже $10 \%$ (рис. 4). Гранулометрический состав кокса также изменился в сторону укрупнения частиц (рис. 5), так как эффект термодробления теперь не оказывает столь значительного влияния на измельчение угля.

Применение подсушенного угля позволило также обеспечить стабильное функционирование кипящего слоя вплоть до температуры $550{ }^{\circ} \mathrm{C}$. В диапазоне $550-680^{\circ} \mathrm{C}$, соответствующих 


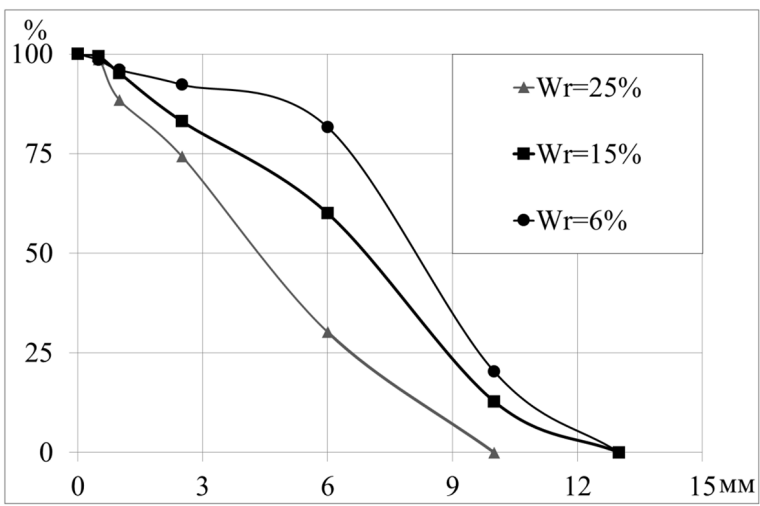

Рис. 6. Средний гранулометрический состав БПК из угля с различной влагой в диапазоне температур $550-670{ }^{\circ} \mathrm{C}$

Fig. 6. Average granulometric composition of BSC made of coal with different moisture in the temperature range $550-670{ }^{\circ} \mathrm{C}$

температурам полукоксования, получен буроугольный полукокс с выходом летучих веществ в пределах 10-22\% (рис. 4). Такой уровень выхода летучих соответствует характеристикам углей марок Т и СC, используемых для вдувания в доменные печи предприятий черной металлургии. Удельный выход полукокса из подсушенного угля достигает 103 кг/ГДж. Помимо этого, как видно на рис. 6, при снижении температуры обработки угля крупность частиц получаемого полукокса возрастает в еще большей степени.

\section{Выводы}

В результате исследований установлена возможность повышения экономической эффективности производства тепловой энергии в типовых котельных агрегатах путем интенсификации энерготехнологической переработки угля в кипящем слое как удалением из угля мелких классов, так и путем его предварительного подсушивания. Удаление мелочи позволяет повысить удельную производительность процесса по твердому продукту в расчете на единицу товарной тепловой энергии более, чем на 50 \% (отн.). Подсушивание угля обеспечивает еще большую интенсификацию процесса термической переработки и повышает удельный выход буроугольного кокса более чем в два раза. При этом радикально снижается стоимость получения тепловой энергии, так как эксплуатационные затраты на ее производство могут быть отнесены на себестоимость дорогостоящего буроугольного кокса.

Кроме того, предварительная сушка угля позволяет расширить номенклатуру выпускаемой в процессе «ТЕРМОКОКС-КС» продукции - от среднетемпературного кокса с значением выхода летучих веществ 7 \% до полукокса с летучими $20 \%$. К тому же ввиду уменьшения влияния эффекта термодробления, возможно получение буроугольного кокса повышенной крупности с улучшенными транспортными характеристиками.

\section{Список литературы / References}

[1] Исламов С.Р. Будущее угля: в поисках новой парадигмы. Уголь, 2018, 9, 26-32 [Islamov S. R. The future of coal: in search of a new paradigm, Coal, 2018, 9, 26-32 (in Russian)] 
[2] Исламов С.Р., Степанов С.Г. Пат. 2359006 РФ, Способ переработки угля, 26.06.2009, бюл. № 17 [Islamov S. R., Stepanov S. R. Pat. 2359006 RF, Coal processing method, 26.06.2009, bul. № 17 (in Russian)]

[3] Исламов С.Р., Баякин С. Г., Михалев И. О. Экологические аспекты современных технологий энерготехнологической переработки угля. Вестник Международной академии наук экологии и безопасности, 2009, 14 (6), 185-189 [Islamov S. R., Bayakin S. G., Mihalev I. O. Environmental aspects of modern technologies for energy-technological processing of coal. Bulletin of the international academy of sciences of ecology and safety, 2009, 14 (6), 185-189 (in Russian)]

[4] Логинов Д.А., Исламов С.Р. Развитие технологии комбинированного использования угля в котлах с кипящим слоем. Промышленная энергетика, 2011, 4, 12-14 [Loginov D. A., Islamov S. R. Development of technology for the combined use of coal in fluidized bed boilers. Industrial energy, 2011, 4, 12-14 (in Russian)]

[5] Логинов Д.А., Деменчук С.В., Исламов С.Р. Новые возможности технологии карбонизации угля в кипящем слое. Кокс и химия, 2020, 11, 9-11 [Loginov D. A., Demenchuk S. V., Islamov S. R. New opportunities fluidized bed carbonization technology. Coke and chemistry, 2020, 11, 9-11 (in Russian)] 